\title{
Practising Place: A Critical Approach to Localism
}

\author{
John Rule \\ University of New South Wales
}

\begin{abstract}
This paper draws on empirical data from my doctoral research on the changing nature of inner city community development work. The professional identity of the community worker emerged in the 1970s and is linked to other emergent identities - the resident activist, social activist and community activist. Inner city community development work is in a state of flux and requires new investigative and analytical tools to help make sense of both its past, present and future. Whilst it is clear that governing patterns have changed considerably since the 1970s, and challenged the role and the potential of what were once considered radical or alternative community development approaches, I argue that it is still possible to identify areas for productive engagement through what I have called practising place.
\end{abstract}

\section{Introduction}

My research covered a limited geographical area, inner city Sydney, but there are theoretical connections that extend beyond inner city Sydney and Australia. Castells (1983, 2004), Dirlik (1996), Massey $(1993,1999)$ and Sandercock $(1990,1998)$ all suggest that 'local practices' should be a focus of research and study in contemporary times. There is a growing body of theory and empirical research that is trying to make sense of the various forms of practice that are emerging under the heading of 'the local'. In this paper I am concerned with two aspects of this larger discussion. Firstly, does there remain any potential for the local to be a site of resistance; and secondly, what are the emergent identities that might enable a progressive activist politics to continue at a local level? As I explore these questions in this paper, it becomes clear that those who engage in political practices of resistance and activism are always challenged because of the power of existing rationalities. Clifford (2001) and Castells (2004) argue that resistance is often 'reintegrated' back into existing social structures; therein lies the dilemma of any activist political practice - how to resist such reintegration.

Based on evidence from key informants, there is some evidence that social change can continue to happen from combined activist struggles. However, in those struggles, those engaged as activists must remain critically aware of the limits of those local practices, and, additionally, must remain aware that the identity of the activist should be fluid, open-tochange and resistant to any form of essentialism. 


\section{Study Method}

Rose (1997) was interested in the way that community is imagined and performed and the potential of resistant community work practices. Rose explored the diverse interpretation of the 'local' and 'community' with a group of community arts workers in Edinburgh, Scotland. I used a similar method of investigation with community workers, who had worked for a range of small inner city Sydney community organisations, Neighbourhood Centres (NCs), from 1975 through to 2005. These community workers (five) were involved in neighbourhood centre work, youth work, family support programs, housing estate development programs and migrant community development programs. In my research I also had regular meetings and dialogic conversations with two people who had a long history of engagement with these organisations and defined themselves as urban and social activists. For Rose there are no assumptions about 'community', the meanings only becoming apparent by the investigation of how community is performed in specific sites. Like Rose, I took the view that the local, the specific, the neighbourhood may be valued as a site of investigation, but a critical or deconstructive approach needs to be applied to the stories and myths that are circulated about community.

\section{Community and Urban Social Movements}

Castells (1977, 1983, and 2004) has monitored the activities of many groups trying to create sensitive and democratic processes to produce liveable cities. Castells initially conceptualised urban social movements as manifestations of class conflict (1977, p.325). In a later study Castells (1983) proposed that there are some basic themes in urban movements and protests, regardless of whether they are tenant struggles, youth organising associations, urban uprisings, or resident and neighbourhood associations. He concluded that resistance takes place around collective consumption issues of housing, schools and welfare provision, or the defence and expression of cultural identities, or around the workings of the state institutions and sometimes, local government, or a combination of these. He saw all this as a form of resistance, a counter to the imposition of global economic and cultural forms of domination. Castells was less hopeful about the potential of 'emancipation' promised by the urban movements as he followed their trajectories over a longer period; he notes the ways in which the movements themselves, their discourses, individuals involved and organisations had often been integrated into government arrangements through differing systems of citizen 
participation and community development activities (2004:65). Later in this paper I recount a similar trajectory of urban social movements in inner city Sydney.

Sandercock $(1990,1998)$ has also focused on urban history and the struggles of citizens, communities and groups to shape cities and impact on planning processes. She has written about these struggles in the Australian context (1990), as well as presenting an extensive international review of attempts to plan for 'multicultural cities' (1998). Under the heading of 'insurgent practices' she argues that there are individuals who she calls 'the mobilizers', these are individuals whose radical local practices are rarely recognised beyond their locality base. In a review of six major cities, Sandercock keeps asking questions of the group she identifies as the 'mobilizers' and these questions are similar to the ones I asked the community workers and activists: What theories inform their community practice? What knowledges are being used in these practices? What are the definitions of community that are being used? What are the processes that groups are using in their struggles with power and what is achieved? Sandercock identifies and seeks out 'the mobilizers' in particular struggles; similarly I have sought out activists and community workers who have played 'organising' or 'mobilising' roles around the development of inner city Sydney Neighbourhood Centre (NCs).

Massey’s locality studies have also been extensive (1993, 1999). Massey argues for a progressive sense of place; otherwise the development of communities constructs a distinction between members and non-members that is exclusionary and intolerant of any sense of 'other'. She argues that if places that are conceived as a set of social relations, (rather than a point which is arrived at, which needs to be preserved and defended), there may be openness to the possibility that others can be accommodated within that set of social relations (1993, p.66-68). I found this 'progressive sense of place'; which is Massey’s conceptual framework developed to resist exclusions, a useful framework to bring to my research. Dirlik (1996) proposes a similar notion in his discussion of ‘critical localism’. He notes that the impact of global capitalism has produced a range of local movements of resistance. He argues that the affirmation of the 'local' comes with a danger of sliding into nostalgia and is amenable to exclusionary tendencies. He argues that 'critical localism' could be developed and from this critical position the local and place can be useful to negotiate the removal of oppressions or inequalities that are inherited from the past. Dirlik sees in this a useful and meaningful resistance to the excesses of global capital, 'The boundaries of the 
local need to be kept open (or porous) if the local is to serve as a critical concept' (1996, p.42).

\section{The Importance of Place}

I argue that in field of community development work a critical examination of place can provide some new analytical and conceptual tools to enliven community development practices. Interdisciplinary work in human and social geography provides an interesting starting point to examine the question of place. In this next section I provide a brief overview of some approaches to community and place which I found useful to bring as conceptual resources to my research, and to developing what I have called 'practising place'.

Sandercock provides a critical history of the way that planning, and particularly town planning, have carved out roles as adjuncts to modern bureaucratic and state power arrangements. The consequence has been a limiting of the potential for the development of inclusive local social formations and communities. In response, Sandercock (1998), dreams of her 'cosmopolis' and searches for her 'postmodern utopia'. This utopia, she argues must always be present but never actually presented. She does not want to impose her utopian vision on others. Sandercock 'scours cities' looking for 'insurgent practices' and evidence of 'one thousand tiny empowerments'. Keith and Pile (1993) and Pile (1997) map 'spaces of resistance'; much of their work concentrates on turbulent inner city environments in England during and after years of rule of the conservative Thatcher government. They sought to show how '...fragmentation, ruptures and discontinuities can be politically transformed from liability and weakness to opportunity and strength...' (Keith \& Pile 1993, p.193). Concentrating on Los Angeles as the exemplar of the modern metropolis, Soja (1996), uses the concept of a 'third space'. The third space is a metaphorical space in which 'difference' is marked for potential rather than limitations. By paying attention to the possibilities of this third space, which is not unreal but an imagined place, new social patterns could be formed, patterns which are supportive of difference rather than social patterns that are based on a fear of difference. Harvey goes, from 'place to space and back again’ but always with the starting point that '...place in whatever guise...is a social construct' (Harvey 1993, p.7). Watson and Gibson (1994), Wilson (1991) and Zukin (1992) search the streets of postmodern cities, often, and particularly in the case of Wilson, the streets of inner cities or city centres tracing a feminist storyline. Watson and Gibson (1995) study Australian cities and the way in which the urban and place is 'thought', they try to overlay that thinking with a social justice 
framework. Wilson emerges from her tours of the 'labyrinth' with '...a new, 'feminine' voice in praise of cities' (Wilson 1991, p.11). Zukin calls for a professional commitment to 'liminality', to supporting by whatever means, those who are not given a place within highly territorialised city spaces (1992, p.242).

In my research I was interested in how the activists and community workers imagine their place, in the interviews and conversations with activists and community workers I tested out the possibility that place could be envisaged as utopia, as transformation, as inclusive rather than exclusive, as a social construct and as a place of liminality. Like Sandercock and the other authors who I have referred to as radical and critical human geographers, I adopt the epistemological stance that we know what we know, through being in a place, and through participating in constructing the sets of social relationships within that place.

\section{Research Context}

Barry, Clohesy and Smith (1985) provide a history of inner city Sydney community and neighbourhood work. They describe the pre-conditions for the emergence of resident and community action groups and neighbourhood associations in the 1960s. These included: technological changes to traditional employment of labour on the waterfront; threatened job losses (in the manufacturing sector); an increase in speculative land development; an expansion of tertiary institutions into residential areas of Darlington and Chippendale; expressways planned through Glebe, Ultimo, Pyrmont, Woolloomooloo and Darlinghurst; and actions by the state Department of Housing in Surry Hills and Redfern which were forcing changes to the working class residential base of pockets of inner city Sydney. Resident Action Groups brought together individuals who felt threatened by these changes, planners who thought that there could be more effective ways of managing inner city environments and sections of the student movement attending local universities, who at that time, were looking for effective change strategies beyond the provision of welfare services.

The organisations that emerged through this process were marginal to the extent that they concentrated on information, advocacy and social action for groups who had traditionally been locked out of government planning processes. For example, the Coalition of Inner Sydney Resident Action Groups was formed in 1972 with a brief to focus on housing; transport and energy; education and community services. Jakubowicz $(1974,1984)$ questioned the class based nature of urban environmentalism and the difficulties of defending 
'urban' working class interests within these resident movements, and he noted the importance of cross-class alliances, as did Barry, Clohesy and Smith (1985). Mundey (1987) and Burgmann and Burgmann (1998, pp.56-58) document the connections between the inner city Resident Action Groups and the environmental activism of the NSW Builders Labourers' Federation. They also note the cross-class alliances, between residents and unions, and amongst resident groups, as well as drawing attention to the central role played by women in these actions.

The Australian Assistance Plan (AAP) instituted by the Whitlam government established a public policy and funding framework in which new organisations developed. The AAP provided seeding funding for many small community-based initiatives, including the Neighbourhood Centres (NCs). The 1970s saw a growth in co-operatives and community associations, usually taking on some form of local resident management structure, and seeking to employ professional staff in the roles of co-ordinators and community development workers (Roberts \& Pietsch 1996, p.144). The NCs early links to the environment and feminist movement, as well as their role in supporting cultural diversity through multicultural project initiatives is described by Edwards (1996) in a report sponsored by the Inner Sydney Council for Regional and Social Development.

By the end of the 1980s discourses of environmentalism, feminism and multiculturalism were still evident in the community organisations, but other discourses connected with increasing professionalisation, new managerialism and new funding regimes were beginning to circulate. They did not entirely erase those earlier discourses but introduced a new set of tensions. As noted by Barry, Clohesy and Smith (1985) 'efficiency' and 'management rhetoric' came to dominate community focused projects and development work. Yeatman (1990) characterised the preceding decade as a period of struggle between the managerial agenda of the state and grass roots efforts to democratise political processes in Australia; the micro techniques of scientific management were applied to social services and welfare provision became market oriented and privatised. This accompanied increasing government monitoring of funding contracts and more detailed reporting procedures. A report produced in 1994, 'We Just Grew like Topsy', by the Local Community Services Association of NSW, a peak body for community and neighbourhood centres, suggested that in this decade small community based organisations were overwhelmed by a raft of new government directed programs, these programs had strict and generally unmanageable service delivery 
expectations and reporting requirements. This change was also noted by Williams and Onyx (2002).

Reviews of community work practice in Australia by Kenny (1994), and Weeks, Hoatson and Dixon (2003) have noted the ways in which movements based on different structural features - race, gender, sexuality, ecology, class and social identity - became active and collectively organised through community development activities in the 1970s. They also note that these movements and the organisations which grew up around them were in a sense forced 'underground', or, at least their activities curtailed, in late 1980s and 1990s because of the recasting of social issues as ‘individual problems and individual responsibilities'.

Everingham (2001) provides a detailed account of the way in which economic rationalism impacted on the community sector. She argues those organisations that had drawn ' ...their inspiration from the emancipatory objectives of the new social movements... in the 1960s...' were, after 'Two decades of public service reforms under economic rationalism', in the position where their autonomy and roles within community were severely eroded (2001, p.108). The language of mutual obligation and contractualism brought about a new politics where 'community' was charged with the responsibility of being an agent for implementing a government directed agenda. Further, through a contract state paradigm that became evident in the mid 1990s, government (at local, state and federal levels) has linked community organisation activity to a series of contracted service arrangements with very specific, limited measurements and service outputs (Hoatson, Dixon \& Stoman 1996; Everingham 2001).

The above highlights the changed focus of the organisations as political and economic changes occurred and as other discourses, for example economic rationalism, contractualism, and mutual obligation, came to dominate social processes. The conservative social policy paradigm continued through to the present, and its impacts on alternative social formations at a local community level over the last number of years is well documented (Darcy 2002; Suehood, Marks \& Waterford 2006; Keevers, Treleaven \& Sykes 2008; Onyx, Dalton, Melville, Casey \& Banks 2008)

This brief history of the emergence of locally based community organisations in inner city Sydney, and how they have been impacted by national social policy changes, provides a context in which to locate the accounts of practice which follow. 


\section{Dialogic Conversations with Activists and Community Workers}

The Neighbourhood Centres have been sites where particular identity formations have been made possible. The identity of 'generalist community worker' for example, is an identity position made possible because of the emergence of local community organisations. Clifford (2001) describes local sites as 'enunciative modalities' and is interested in seeing what forms of political subjectivity and identities are activated in different local sites. Enunciative modalities, according to Clifford, '...can help us to define and delineate those spaces, or sites, in which individuals fashion their own identity as political subjects' (Clifford 2001, p.11)

The identities of 'resident activist', 'urban activist', 'social activist' and 'community worker' have only been constructed (and available) in the last forty years. Based on my research I suggest these identities have been occupied, or taken up, in the inner city NCs in ways that are distinctive of those sites, and, certainly, shaped by the urban social movements discussed earlier. The participants in this research have adopted those positions and mobilised particular discourses from those positions, to do what I have labelled 'practising place'. Further, being able to mobilise those identities has been an essential part of that practice where place is not just a statement about geographical location but takes on the dimensions of 'standpoint', 'perspective' and 'position'. There are similarities to the politics of location described by bell hooks:

As a radical standpoint, perspective, position, 'the politics of location' necessarily calls those of us who would participate in the formation of counter-hegemonic cultural practice to identify the spaces where we begin the process of re-vision (hooks 1991, p.145).

Rose (1997) interviewed community arts workers in Edinburgh, who were fluent in left liberal discourses of community development and empowerment. Those she interviewed were also critical of those discourses, although interested in how they were activated. They saw their community project work and activities as a place to which their own identities and political positions were bought, and within which they were shaped. In my research around the NCs participants indicated a similar awareness, both in terms of the discourses in which they are enmeshed, and, the ways in which identities are shaped by, and shape those discourses. 
Castells (2004), Dirlik (1996), Massey (1993, 1999) and Sandercock (1998) place some form of identity story at the centre of the story of urban social movements. Sandercock describes these social movements, most visible in inner city environments and politics, as not just promoting a form of 'identity politics' but as moving 'towards a progressive politics of difference'. Sandercock argues that this identity work is really the most important aspect of planning that is sensitive to community, environment and cultural diversity. She develops the argument that the task is not one of just concentrating on the positives of difference, but of unmasking 'the social construction of identities' (1998, p.123).

In my research the activists (Enid and Neil) provided very detailed accounts about their life history as activists. They described in detail what they thought it meant to be an activist; they described how it came to be that they took up this subject position and how their own personal histories were a part of that. The issue of identity became part of the conversation with the activists; they explained what they meant by the activist identity and critically examined its effects.

The community workers, (Carla, Michael, Monica, Sarah and Tevi) also talked about their own subject positions and identities. Quite often in the transcript data these kinds of statements were found: '...as a community worker I operated in this way...' and 'As a feminist I think...' and 'From a structuralist position I see it like this... ‘. Other statements included: 'Because I grew up in a working class background...' and 'My migrant experience leads me to take this view...' These identities of community worker, feminist, structuralist and migrant were often put forward as a way of explaining positions and became part of the conversations. It was clear that the community workers saw that their ways of working and their practices were deeply enmeshed with ‘who they were' and with their identities.

\section{The Activist Position}

Healy (2000) argues that the 'heroic activist' is a deeply gendered construction which needs to be opened up to multiple identifications. In the sections that follow it becomes clear that the activists I interviewed did not assume that the activist label situates them as, ' ... heroic actors who stand outside the systems of power and speak the truth to them' (Healy 2000, p.135 following on from Foucault). Rather, the activists in this research describe what they have done in the course of their 'daily practices' and find that the activist label is applied to them, often because in these daily practices they are positioned as challenging power 
relationships and the label of activist is a way of discrediting their daily practices and actions. The labelling often came from those who 'speak with power', as a deliberate strategy to position their (the activists) actions in a marginal place. Moreover, the activists do not describe their actions as 'heroic'. As one of them explains, the only thing that they did, was to 'contest authority' and this placed them in a contrary position to 'authority' and led them to be constructed in negative and pejorative ways by those positioned with institutional authority. Enid and Neil acknowledge they are not completely in control of their own naming, or identity position; quite often that identity position, the position of activist, is forced upon them by the social structures in which they operate.

In considering the ways that political subjectivities emerge in the governmentalised state, Clifford (2001), draws attention to the political subject of the activist. He is interested in the figure of the activist, because of the potential of this subject position. As he describes it, the subject position of the activist, which exists within the 'interplay of discourse, power and subjectivation', has radical potential because '...we cannot...underestimate the effect of even a single political subject on the experience of the social body as a whole' (Clifford 2001, p.123). Notwithstanding the important potential of the political subject position of the activist, Clifford suggests that there is a danger that activist political practices are easily reintegrated into existing political structures and rationalities. I raised this dilemma during the dialogical conversations and it elicited the following responses.

\section{Enid's Story of the 'Urban Activist' Position}

Enid called herself an 'urban activist'. The following transcript material provides an account of what she means by the expression 'activist':

There was a lot of activity going on in the seventies and there were a lot of people who might not have called themselves an activist although it [activism] was certainly there. There was another expression - urban guerrilla - I liked that one. That idea of the urban guerrilla...how can I say... it so shocked a lot of people including the bureaucracy, but not all of the bureaucrats because after all, these 'guerrillas' often became part of the establishment! So that it [the activist position] may well be a mythic position but it was certainly there.

I have great faith in that that word [activism] does come up. I've experienced it myself. It really represents the change that occurred in Australian society from people who were prepared to go out and have a go - the public demonstrations. The demanding baby boomer group who were busy fighting about the Vietnam War, they were extremely aggressive people and rightly so. Many of us were part of that, perhaps not as violent as some. Also the 
environmental movement. The women and environment movements were the two most important [activist] movements.

And at that time in our inner city the big thing was that the older suburbs were part of a town planning process that was about the demolition and slum clearance... that policy had been around for many years and Northcott [a housing department site in Surry Hills] was created as part of that policy. When asking the building labourers to come in [reference to the Green Bans of the 1970s], everything there was aggression. Aggression against outmoded ideas, but that was the only way in which we could get through, we had to be aggressive in our own way.

'It's always been like that', is the existing rationality that the activists have had to approach. I think it is one of the most difficult things working at local level you hear people say - 'It's been like that for years and that's the way we like it!'

It takes a skilled person, or a lot of activists and guerrillas to come in and say; 'look this is another way of doing it - it can be different!'

This story, like that of Neil's, which follows, is about contesting authority. Enid describes the shaping of the activist identity as arising out of engagement in social processes and political discourses. Enid describes the identity position of the activist as being shaped and re-shaped, necessarily fluid in the context of her own social practices. Enid addresses the kinds of questions raised by Clifford (2001), recognising that by adopting different identities and subject positions e.g. one moment 'urban guerrilla' and next moment 'urban guerrilla as a member of the establishment', that the existing rationalities could be challenged and that real social change could happen through combined activist struggles.

\section{Neil's Story of the 'Social Activist' Position}

Neil described what he meant by social activism. Contrary to any notion of 'heroic activism', Neil suggests that the subject position of the activist is an inevitable place to be situated if one is to engage with 'authority' in particular forms. It is a place where people are often positioned when they make an attempt to shift systems of power. Because 'difference' and 'authenticity' are often denied in social processes, this forces those who are different, or who act with authenticity, into a contest with those who try to deny differences and 'struggles for freedom'. Neil tells his story of the experience of being positioned as an activist and dissenter. Neil says that these positions are constructed in a particular discursive field. However, he argues that it is by recognising the way that the construction of the activist position occurs, that is, by a continual process of deconstruction, that it is possible to open up 
and continually re-construct and re-enliven the social activist position. Neil wrote the following to explain what he meant:

For me to talk about being an activist, about community work or community action means to say these things:

1) having an intent to act collectively in the midst of and focussing on the collectivities that do arise and which might arise within our society, these being the sites where society/social beings are shaped

2) deconstructing the social shaping/the social conditioning or identity making which takes place - particularly exposing the apparentness of that social shaping i.e. it is not natural, not essential, and passes away - which embraces calling into question all assumed authorities and titles, including my own - particularly calling into question the corruptness of the social shaping

3) saying "yes" to alternative social identities - this is the act of dissent - it is made out to be "no-saying" but that is the language of the Master - it is actually "yes saying" for those with the ears to hear - it is about maintaining the alternative identities - a process of continual coming out, a continual affirmation

4) doing some work together - a project - preferably some work which is sweaty, requiring great effort and attention, and demanding that we work together.

I'll speak briefly about what this means in being an activist. It's to do with the collective work I've mentioned above. I suppose we can talk about being a dissenter in private, although I really think to talk in that way is to talk nonsense. What I'm saying is that to be a dissenter is to also be a contester i.e. to be public, to be out. What brings me into being a dissenter also brings me into being a contester - what we call an activist. What brings about or triggers me into being a social activist is not my desire to colonise those I'm said to dissent from, not my desire to impose on those people a compliance for themselves with my alternative - no, what brings me into the arena of contest is when I experience the acts/utterances of these other people as not respecting me as I am, and desiring to conform me and my world from as it is, to what they want it to be. It is when my difference, my authenticity, is denied.

Neil suggested that one of the roles of activism is that of 'deconstructing' the social shaping, conditioning and identity making that takes place, and, of seeking out and saying 'yes' to emergent social identities which often means acting in non-compliant ways in the social arena. According to Neil, in assuming the social activist position, as an authentic expression in struggling with power, social activists are made vulnerable because the authentic difference of those who dissent is denied.

For Enid and Neil their identification with the activist position has happened through necessary engagement in a variety of political contests. They see themselves as contesting authority; both describe how they were positioned as aggressive, or how in attempting to gain attention and bring about change they had to adopt an aggressive or oppositional posture. 
Rutherford (1990) describes identity construction as a search for some kind of personal coherence. Rutherford uses the image of identity as a 'home'; that is place where people 'speak from'. The identity work above does not support this way of understanding identity the activists have not suggested that the activist identity provides any support or the kind of comfort that the image of a 'home' sets up. Perhaps the stories above have more in common with the kind of ethical citizenship and identity practices described by Watney which have at their core a '... refusal of both the values of capitalism and the institutions of parliamentarianism as it is currently practiced and understood' (1990, p.159). For the activists, those identity positions of social activist and urban activist have been more closely aligned with a 'practice of freedom' (Watney 1990) than an interest in shaping identity for identity's sake. Neil and Enid would probably agree with the criticism that Bauman (2001) makes of 'identity games'.

My aim in this section has not been to interpret what the activists have said about their identities but to show that they think 'identity work' is an important part of their practice. This is an argument I have developed, that a feature of practising place, is the ability to work with different identities but to work in such a way that opens up different and varied identity formations rather than having the effect of 'fixing', 'stabilising' or 'concretising' identities.

\section{The Critical Community Worker Position}

In the dialogic conversations and semi structured interviews the community workers often said that the motivation for their actions came from a desire to bring about some form of social change. They described their attempts to intervene and to shape social arrangements in a way that re-arranged power structures. These desires to bring about change are an important part of the identity of the community workers. In talking with them, recognising their powerful sense of agency, and hearing their descriptions of what they set out to do, and what they hoped to achieve, I was reminded of the description used by Weedon of 'conscious thinking subjects' who are attempting to give some 'meaning to the material social relations' (Weedon 1997, p.26) in which they find themselves. Weedon goes on to say, that the ability to live like this depends on the ability to access 'social power and discourses' that have some political strength. The community workers talked often about trying to achieve that political strength. 
The community workers talked about what they set out to do, what they intended in their community work practices. They describe their work as existing within a mesh of political discourses and power relationships. They analyse the operation of power and how it manifests at a local level. Quotes demonstrating this are set out below. They talked about government, communities, developers, funding processes and their own interventions to balance or rebalance power. The community workers are suspicious of power used by bureaucracies or the private economic interests of developers. They described political and personal decisions they made along the way. They talked in detail about the forms of community practices they wanted to enact. They talked about using 'institutional power' and the possibilities of 'direct action' when other forms of intervention are failing. They talked about their desires for 'social justice' and 'equality' and their understandings of the methods by which this might be achieved.

As with the community arts workers interviewed by Rose (1997) the community workers involved in my research had a 'left liberal literacy’ and a suspicion of the hegemonic practices that they see as present in contemporary Australian society. Below is material from the transcripts where the community workers talk about what they were doing and through this a picture develops of how the community workers understand their various identities.

Carla: $\quad$ I think it's more about what we were really doing was trying to predict the future...You know I think what really goes on is looking at what the funding bodies want to fund; and assessing what you really need funding for and trying to match that need to what's available and try to satisfy both sides. And so I think that what we were really doing was about trying to predict the future in a way.

Sarah: Well I guess we thought we were about opposition. But I suspect we were probably partly about social control. That's my take on it now looking back at that time. At the time I thought that what we were doing was empowering people on the estate by informing them about what was really happening.

Michael: I was certainly attracted to the community sector ten or twenty years ago, because of the range of activities, the nature of the strategies they were using, those commitments to inclusive processes...it was personally empowering and politically empowering. Those social movements at the time, whether you look at issues around gender or race or environmentalism and the questioning of social order in the early and mid seventies, I then found the community sector in the period that I first saw it in the eighties as being a field where those ideas came into practice. 
Monica: Well we were trying to change things. I mean we were trying to make things better for those people. We thought we knew what would be better for those people. And we wanted there to be more justice. You know we wanted there to be more equality, that's what it was all about. We started off by talking about equality for women and that made us realise, or certainly made me realise, that it wasn't just women who weren't equal, but there were a whole lot of people who weren't equal.

Tevi: $\quad$ Being the meat in the sandwich...that's what it felt like...I was trying to get the best outcome I could for the communities. Sometimes I don't think that was actually right, we compromised, but it was the best possible outcome. So trying to mediate between community expectations and what developers, governments, organisations wanted to do. Your personal political views quite often need to be set aside and so that's why the meat in the sandwich sort of thing.

The community workers, like the activists were also narrating their identities. They were describing how their sense of 'self' both shaped the work in which they were involved and how they were in turn shaped by those experiences and practices. While there were doubts expressed about what was actually achieved through these practices there is a clear sense of how these community workers saw themselves - they saw themselves as 'oppositional', 'committed to inclusive processes', 'questioning of the social order', 'trying to change things politically' and 'mediating' between communities, developers, government and other organisations.

These community workers saw themselves as having a 'critical awareness' in the sense of having an orientation to critical theory in their analysis of society and social structures. They were familiar with and identified strongly with feminist and socialist traditions. They saw themselves as active (although not always 'successful'), in engaging in political processes and working with power.

\section{Dimensions of Practising Place}

\section{Practising Place - a Suspicion of Fixing Identities}

The activists and critical community workers said quite often that their social identities were imposed upon them. Their activism and alternative community work practices placed them in agonistic relationships with power structures, and they were often then labelled or positioned in ways they did not necessarily identify with. They argued that their identities arose in the 'performance' of their activism and community work and some were identities that were ascribed by others rather than identities they wanted to claim. One of the critical community 
workers when talking about the subject position of 'left wing feminist' said that is not always where she would position herself however, '...that's where the language of the culture positions us...'

The activists, when talking about their work said that at times they were positioned as 'aggressive' and as 'trouble makers' by those who held some form of institutional power but in fact their own strategies were ones that tried to avoid 'outmoded' methods such as acts of aggression. The activists and community workers in the 'performing' those roles were often given identities that did not want to claim - they did not want their identities fixed.

Research participants expressed a reluctance to see either their own 'selves' as fixed in terms of being activists or community workers and were suspicious of defining community or community participation in a way that 'fixed' either their own identities or the identities of those with whom they worked. 'Practising place' remains suspicious of attempting to fix or make 'concrete' identities. As suggested by Agemben (1993) the way to 'becoming community' may be through a search for 'non-essentialised identities' and may rather be understood as a practice of 'un-working identities'.

\section{Practising Place - a Suspicion of Utopias}

Whilst each of the research participants voiced, during some stages of the research, their imaginings of social futures and perhaps even their social utopias, some of the participants remained sceptical about mapping out what that utopia may be. There was a suspicion stated about utopian thinking and certainly an argument was developed (similar to that proposed by Sandercock 1998) that 'my utopia is not yours'. There was an acknowledgement by the research participants that history and the history of some community development work projects demonstrate the dangers and rigidities of utopias forced upon others. Castells (1997), Dirlik (1996), Massey $(1993,1999)$ and Sandercock (1998) argue that utopias cannot be imagined alone and are always unfinished, contested and necessarily characterised by a space for differences, differences which are positively upheld, within that imagining. The research participants seemed to concur with this approach, supporting the view that one should be suspicious about utopian thinking and be aware that a view of utopia held by one person will not necessarily be the utopia held by another. 
Practising Place - the Importance of Becoming Communities

Agamben (1993) inserts the notion of 'singularities’ into his analysis of becoming communities, arguing that new forms of 'collectivisation' wherein 'new types of nonindividuated subjectivity' are always forming. These will arise and coalesce regardless of the intervention or non-intervention of the state apparatus. The state cannot tolerate or control the fact that there is always this 'birth-to-presence' and always 'becoming communities'. Agamben argues, humans will 'co-belong' whether state apparatus allows them to or not. This is because the State cannot, ultimately do anything about the 'becoming-ness', the State cannot stop the inevitable and potential co-joining of singularities. As Tevi, one of the research participants said '...the other will always connect, even if it is to the next stage'.

One of the research participants made this summary statement, 'I don't have a definitive social future. And there are many people like me and more and more of us. We don't have any definitive social future because it is so diverse.' Through their refusals to describe the shape of their imagined social futures, the activists and critical community workers continue to inhabit their own diverse and resistant geographies - such resistance is also a dimension of practising place.

\section{Community Development, Activism and Emergent Identities}

This paper, based on my research, describes a particular location which is always in a state of flux, of change, of impermanent social arrangements and social identities. I have proposed another way of talking about activist and community development work in inner city Sydney - I called that practising place. The identity of the community activist, resident activist, social activist and the local community worker emerged in the last forty years and practising place will need to stay alert to other emergent identity positions. Those who wish to maintain progressive activist politics and community development work in these places will need to adopt a position of 'becoming'; wherein identities and relationships must, necessarily remain in a state of constant of negotiation and change; wherein the identities of the activist and community development worker, to be productive into the future, will need to resist being essentialised and will need to be critically un-worked and re-worked.

\section{Bibliography}

Agamben, G. 1993, The Coming Community, (Trans. M. Hardt), University of Minnesota Press, Minneapolis. 
Barry, M., Clohesy, M. \& Smith, P. 1985, 'Inner city resident action', in R.Thorpe and J.Petruchenia (Eds.) Community work or social change? An Australian perspective, Routledge, London, pp. 81-95.

Bauman, Z. 2001, Community: Seeking Safety in an Insecure World, Polity Press, Cambridge.

Burgmann, M. \& Burgmann, V. 1998, Green Bans, Red Union, University of NSW Press, Sydney.

Castells, M. 1977, The Urban Question, Edward Arnold, London.

Castells, M. 1983, The City and the Grassroots: a Cross-cultural Theory of Urban Social Movements, Edward Arnold, London.

Castells, M. 2004, The Power of Identity, Blackwell, Oxford.

Clifford, M. 2001, Political Genealogy After Foucault, Routledge, London.

Darcy, M. 2002, 'Community management: How management discourse killed participation', Critical Quarterly, vol. 44, no. 4, pp. 32-39.

Dirlik, A. 1996, 'The Global in the Local', in R. Wilson \& W. Dissanayake (Eds.) Global/Local: Cultural Production and the Transnational Imaginary, Duke University Press, London, pp. 21-45.

Everingham, C. 2001, 'Reconstituting Community: Social Justice, Social Order and the Politics of Community', Australian Journal of Social Issues, vol.36, no.2, pp. 105-122.

Edwards, R. 1996, There's Something Addictive about Neighbourhood Centres, Inner Sydney Council for Regional and Social Development, Sydney.

Gibson, K. and Watson, S. (Eds.) 1994, Metropolis Now, Pluto Press, Sydney.

Harvey, D. 1993, 'From space to place and back again: Reflections on the condition of postmodernity’, in J. Bird, B. Curtis, T. Putnam, G. Robertson \& L. Tickner (Eds.) Mapping the Futures: Local Cultures, Global Change, Routledge. London, pp.3-29.

Healy, K. 2000, Social Work Practices, Sage, London.

Hoatson, L., Dixon, J. \& Stoman, D. 1996, 'Community Development, citizenship and the contract state’, Community Development Journal, vol.31, no.2, pp. 126-136.

hooks, b. 1991, Yearning: Race, Gender, and Cultural Politics, Turnaround, London.

Jakubowicz, A. 1974, 'The city game: urban ideology and social conflict, or Who gets the goodies and who pays the costs?', in D.E. Edgar (Ed.) Social change in Australia: readings in sociology, Longman Cheshire, Sydney, pp. 329-344.

Jakubowicz, A. 1984, 'The Green Ban Movement: urban struggle and class politics', in J. Halligan and C. Paris (Eds.) Australian Urban Politics: Critical Perspectives, Longman Cheshire, Sydney, pp. 149-166.

Keevers, L., Treleaven, L. \& Sykes, C. 2008, 'Partnership and participation: contradictions and tensions in the social policy space', Australian Journal of Social Issues, vol. 43no.3, pp.459-477.

Keith, M. \& Pile, S. 1993, 'Introduction Part 1: The Politics of Place' in M. Keith and S. Pile (Eds.) Place and the Politics of Identity, Routledge, London, pp.1-21.

Kenny, S. 1994, Developing Communities for the Future: Community Development in Australia, Thomas Nelson, Melbourne.

Local Community Services Association Incorporated 1994, We just Grew Like Topsy: A resource manual for understanding and managing Multi Purpose Neighbourhood Centres, Local Community Services Association, Surry Hills, Sydney.

Massey, D. 1993, 'Power-geometry and a progressive sense of place', in J. Bird, B. Curtis, T. Putnam, G. Robertson \& L.Tickner (Eds.) Mapping the Futures: Local Cultures, Global Change, Routledge, London, pp. 29-70.

Massey, D. 1999, 'Cities in the world', in D. Massey, J. Allen \& S. Pile. (Eds.) City Worlds, Routledge, London. 
Mundey, J. 1987, 'From Red to Green: Citizen-Worker Alliance’, in D. Hutton (Ed.) Green Politics in Australia, Angus and Robertson, North Ryde, Sydney, pp. 105-121.

Nancy, J-L. 1991, The Inoperative Community, University of Minnesota Press, Minneapolis.

Onyx, J., Dalton, B., Melville, R., Casey, J., \& Banks, R. (2008). 'Implications of government funding of advocacy for third-sector independence and exploration of alternative advocacy funding models', Australian Journal of Social Issues, vol. 43, no. 4, pp. 631-648.

Pile, S. 1997, 'Opposition, political identities and spaces of resistance', in S. Pile and M. Keith (Eds.) Geographies of Resistance, Routledge, London, pp.1-32.

Roberts, R. and Pietsch, J. 1996, 'Community management and social action: Politicisation or parochialism?’, Community Development Journal, vol. 31, no.2, pp.143-152.

Rose, G. 1997, 'Performing Inoperative Community - the space and resistance of some community arts projects', in S. Pile and M. Keith (Eds.) Geographies of Resistance, Routledge, London.

Rutherford, J. 1990, 'A Place Called Home: Identity and the Cultural Politics of Difference', in Jonathon Rutherford (ed.) Identity: Community Culture Difference, Lawrence \& Wishart, London, pp. 9-27.

Sandercock, L. 1990, Cities for Sale: Property Politics and Planning in Australia, Transaction Publishers, Brunswick, New Jersey.

Sandercock, L. 1998, Towards Cosmopolis: Planning for Multicultural Cities, John Wiley and Sons, Chichester, UK.

Soja, E. 1996, Thirdspace: Journeys to Los Angeles and Other Real-And-Imagined Places, Blackwell, Oxford, UK.

Suhood, T., Marks, C., \& Waterford, M. 2006, The Way Forward: Tackling the issues confronting small community organisations, Voice for SONG, Sydney.

Watney, S. 1990, 'Practices of Freedom: 'Citizenship' and the Politics of Identity in the Age of AIDS' in Jonathon Rutherford (Ed.) Identity: Community Culture Difference, , Lawrence and Wishart, London, pp. 157-185.

Watson, S. \& Gibson, K. 1995, Postmodern Cities and Spaces, Blackwell, Oxford.

Weedon, C. 1997, Feminist Practice and Poststructural Theory, (2nd edn.) Blackwell, Oxford.

Weeks, J. 1998, 'The Sexual Citizen', Theory, Culture and Society, vol.15, nos. 3-4, pp. 3552.

Weeks, W., Hoatson, L. \& Dixon, J. 2003, 'Sharing Theory and Practice' in W. Weeks, L. Hoatson, \& J. Dixon (Eds.) Community Practices in Australia, Pearson, Sydney, pp. 1-8.

Williams, F. \& Onyx, J. 2002, Odd socks: Why the survival of small community services organisations is critical, Local Community Services Association, Sydney.

Wilson, E. 1991, The Sphinx in the City, University of California Press, Berkeley.

Yeatman, A. 1990, Bureaucrats, Technocrats, Femocrats, Allen and Unwin, Sydney.

Zukin, S. 1992, 'Postmodern urban landscapes: mapping culture and power', in S. Lash and J. Friedman, (Eds.) Modernity and Identity, Blackwell, Oxford, pp.221-247. 